\title{
Research on Features of Return in Chinese Stock Market Based on GARCH Model
}

\author{
Xinyi Dang \\ Southwestern University of Finance and Economics \\ dangxinyi@163.com
}

\author{
Qiang Zhang \\ ShenzhenSunfor Light CO.LTD \\ sunfor@126.com
}

\begin{abstract}
The main purpose of the research is to test some features in Chinese market with GARCH family. GARCH can capture volatility clustering in stock market. GARCH-M is applied here to verify that stocks with high risk tend to pay high return. TGARCH and EGARCH illustrate the existence of asymmetries. These features might be of help for investors of Chinese stock market.
\end{abstract}

Keywords-GARCH family; volatility clustering; leverage effect; Chinese stock market

\section{INTRODUCTION}

In 1990, two big Chinese Stock Exchanges were established in Shanghai and Shenzhen. Along with economic growth and market-oriented process, Chinese stock market has exerted tremendous attraction on many. Having studyed asset return in developed financial markets, people found out that dramatic volatility always follows dramatic one and small volatility always follows small one, which called volatility clustering. Also, leverage effect, the tendency for volatility to rise more following a large price fall than following a price rise of the same magnitude, is presented in most stock market. What is more, financial asset return tend to have distributions that accord with leptokurtosis. In addition, highly risky assets are supposed to pay relatively high return for compensation. Chinese stock market is not martue when compared with some western stock markets, and people cannot certainly claim that these common phenomena exist in the young stock market. The main purpose here is to test and verify that some common features also exist in Chinese market.

\section{DATA AND MODEL}

\section{- A. Data}

Shanghai Stock Exchange and Shenzhen Stock Exchange are two most important stock exchanges in China, which can be representative when Chinese stock market is studied, and return rates are collected from both of them, separately. Daily return rates from Jan 1st, 2003 to Dec 31st, 2012 are collected.

- B. Model

According to Akaike's information criteria, the return rate in Shanghai Stock Exchange can be better expressed with $\operatorname{ARMA}(2,2)$ while $\operatorname{ARMA}(3,3)$ works better for Shenzhen Stock Exchange. Models with no more than three lags are relatively convenient to handle and it is easier to interpret the coefficients, so models with more lags are not considered. The conditional mean equations for these two stock markets will be as following, respectively:

Returnrate in Shanghai Stock Market
$=C_{0}+C_{1} \operatorname{ar}(1)+C_{2} \operatorname{ar}(2)+C_{3} m a(1)+C_{4} m a(2)$

Return rate in Shenzhen Stock Market

$=C_{0}{ }^{\prime}+C_{1}{ }^{\prime} \operatorname{ar}(1)+C_{2}{ }^{\prime} \operatorname{ar}(2)+C_{3}{ }^{\prime} \operatorname{ar}(3)+C_{4}{ }^{\prime} m a(1)+C_{5}{ }^{\prime} m a(2)+$ $C_{6}{ }^{\prime} m a(3)$

If the $\mathrm{ARCH}$ effect exists in the two stock markets, ARCH model can be used to analyze clustering volatility and leverage effect. Mean equations for two stock markets are the two equations above. Conditional variance equation in GARCH:

$$
h_{t}=\alpha_{0}+\sum_{i=1}^{q} \alpha_{i} u_{t-i}^{2}+\sum_{j=1}^{p} \beta_{j} h_{t-j} .
$$

Generally, $\operatorname{GARCH}(1,1)$ can capture the feature of, so $\operatorname{GARCH}(1,1)$ is applied.

TGARCH is presented below, which contains an additional term accounting for possible asymmetries:

$$
\begin{gathered}
h_{t}=\alpha_{0}+\alpha_{1} u_{t-1}^{2}+\beta_{1} h_{t-1+} \varphi u_{t-1}^{2} I_{t-1}, \\
\text { where, } I_{t-1}=1 \text { if } u_{t-1}<0 \\
=0 \text { otherwise }
\end{gathered}
$$

EGARCH is also useful to analyze asymmetry, Conditional variance equation for EGARCH:

$$
\begin{gathered}
\log \left(h_{t}\right)=\alpha_{0}+\alpha_{1}\left(/ u_{t-1} / / \sqrt{ } h_{t}-\sqrt{ }(2 / \pi)\right)+ \\
\beta_{1} \log \left(h_{t-1}\right)+\sigma^{*}\left(u_{t-1} /\left(h_{t-1}\right)^{0.5}\right)
\end{gathered}
$$

In order to research the relationship between risk and return, GARCH-M model is exhibited. Standard deviation, whose coefficient is $\lambda$, is added in the conditional mean equation.

\section{Statistical AnAlysis}

\section{- A. Basic Information}

Mean values for Shanghai Stock Exchange is 0.0349, and that for Shenzhen Stock Exchange is 0.0499. Skewness value for Shanghai Stock Exchange is -0.111302 and that for Shenzhen Stock Exchange is -0.384058 . Thenonzeroskewness values declare that the distributions of return rates in both Shanghai Stock Exchange and Shenzhen Stock Exchange are asymmetric. Kurtosis values for Shanghai and Shenzhen stock market are 6.400175 and 5.399016, respectively, which are greater than 3, so fat tail phenomenon also exists. Jarque-Bera values for both stock markets state that the return rates in the two stock markets are not normally distributed--Jarque-Bera values for Shanghai and Shenzhen Stock Exchanges are respectively 1174.620 and 641.9305 .

- B. $A D F$ Test

\begin{tabular}{|c|c|c|}
\multicolumn{2}{c}{ TABLE I: RESULT FROM ADF TEST } \\
\hline & Shanghai & Shenzhen \\
\hline intercept & $-10.75935(0.0000)$ & $-13.46233(0.0000)$ \\
\hline $\begin{array}{c}\text { Trend and } \\
\text { intercept }\end{array}$ & $-10.76834(0.0000)$ & $-13.45992(0.0000)$ \\
\hline none & $-10.76834(0.0000)$ & $-13.42260(0.0000)$ \\
\hline
\end{tabular}


In the ADF test, lag length for Shanghai is 14 and that for Shenzhen is 10 based on AIC. The return rates for both markets are stationary.

- C. ARCH-LMTest

\begin{tabular}{|c|c|c|} 
TABLE II: RESULT FROM ARCH-LM TEST \\
\hline & Shanghai & Shenzhen \\
\hline F-statistic & $28.68224(0.0000)$ & $34.25422(0.0000)$ \\
\hline Obs*R-squared & $135.7087(0.0000)$ & $160.3221(0.0000)$ \\
\hline
\end{tabular}

At $1 \%$ significance level, the null hypothesis, all the coefficients of squared residuals are zero simultaneously, is rejected. There is ARCH effect in Shanghai and Shenzhen stock market. Then the ARCH models will be established.

\section{RESULT AND DISCUSSION}

- A. Estimates from GARCH Family

After the models have been established, estimates, on which the analysis is based, are shown in the following tables.

TABLE III: SHANGHAI STOCK EXCHANGE

\begin{tabular}{|c|c|c|c|c|c|}
\hline \multirow{2}{*}{\multicolumn{2}{|c|}{ Coefficients }} & \multicolumn{4}{|c|}{ Models } \\
\hline & & \multirow{2}{*}{$\begin{array}{c}\text { GARCH } \\
0.029100 \\
(0.025986)\end{array}$} & \multirow{2}{*}{$\begin{array}{c}\boldsymbol{G A R C H}-\boldsymbol{M} \\
-0.134752 \\
(0.093524)\end{array}$} & \multirow{2}{*}{$\begin{array}{c}\text { TGARCH } \\
0.020570 \\
(0.027948)\end{array}$} & \multirow{2}{*}{$\begin{array}{c}\text { EGARCH } \\
0.007257 \\
(0.037574)\end{array}$} \\
\hline \multirow{6}{*}{$\begin{array}{c}\text { Conditional } \\
\text { Mean } \\
\text { Equation }\end{array}$} & $\gamma_{0}$ & & & & \\
\hline & AR(1) & $\begin{array}{c}-1.385692 \\
(0.222371)^{* *}\end{array}$ & $\begin{array}{c}-1.370312 \\
(0.079568)^{* *}\end{array}$ & $\begin{array}{c}-1.397782 \\
(0.199891)^{* *}\end{array}$ & $\begin{array}{c}0.069436 \\
(0.076846)\end{array}$ \\
\hline & $\operatorname{AR}(2)$ & $\begin{array}{c}-0.483129 \\
(0.178799)^{* *}\end{array}$ & $\begin{array}{c}-0.467389 \\
(0.094874)^{* *}\end{array}$ & $\begin{array}{c}-0.494729 \\
(0.160356)^{* *}\end{array}$ & $\begin{array}{c}0.880637 \\
(0.067173)^{* *}\end{array}$ \\
\hline & MA(1) & $\begin{array}{c}1.401301 \\
(0.226487)^{* *}\end{array}$ & $\begin{array}{c}1.384674 \\
(0.080020)^{* *}\end{array}$ & $\begin{array}{c}1.414063 \\
(0.203836)^{* *}\end{array}$ & $\begin{array}{c}-0.044148 \\
(0.073677)\end{array}$ \\
\hline & MA(2) & $\begin{array}{c}0.480062 \\
(0.189107)^{*}\end{array}$ & $\begin{array}{c}0.463295 \\
(0.092868)^{* *}\end{array}$ & $\begin{array}{c}0.492214 \\
(0.169784)^{* *}\end{array}$ & $\begin{array}{c}-0.888726 \\
(0.062347)^{* *}\end{array}$ \\
\hline & $\lambda$ & & $\begin{array}{c}0.121123 \\
(0.65850)\end{array}$ & & \\
\hline \multirow{5}{*}{$\begin{array}{c}\text { Conditional } \\
\text { Variance } \\
\text { Equation }\end{array}$} & $\alpha_{0}$ & $\begin{array}{c}0.023823 \\
(0.005735)^{* *}\end{array}$ & $\begin{array}{c}0.024575 \\
(0.005772)^{* *}\end{array}$ & $\begin{array}{c}0.026732 \\
(0.006196)^{* *}\end{array}$ & $\begin{array}{c}-0.090115 \\
(0.008657)^{* *}\end{array}$ \\
\hline & $\alpha_{1}$ & $\begin{array}{c}0.054106 \\
(0.006116)^{* *}\end{array}$ & $\begin{array}{c}0.055159 \\
(0.006193)^{* *}\end{array}$ & $\begin{array}{c}0.047320 \\
(0.007083)^{* *}\end{array}$ & $\begin{array}{c}0.132700 \\
(0.012496)^{* *}\end{array}$ \\
\hline & $\beta_{1}$ & $\begin{array}{c}0.937501 \\
(0.006924)^{* *}\end{array}$ & $\begin{array}{c}0.936191 \\
(0.007006)^{* *}\end{array}$ & $\begin{array}{c}0.934021 \\
(0.007018)^{* *}\end{array}$ & $\begin{array}{c}0.989255 \\
(0.002640)^{* *}\end{array}$ \\
\hline & $\varphi$ & & & $\begin{array}{c}0.018155 \\
(0.008061)^{*}\end{array}$ & \\
\hline & $\sigma$ & & & & $\begin{array}{c}-0.017077 \\
(0.006337)^{* *}\end{array}$ \\
\hline
\end{tabular}

TABLE IV: SHENZHEN STOCK EXCHANGE

\begin{tabular}{|c|c|c|c|c|c|}
\hline \multirow{2}{*}{\multicolumn{2}{|c|}{ Coefficients }} & \multicolumn{4}{|c|}{ Models } \\
\hline & & GARCH & GARCH-M & TGARCH & EGARCH \\
\hline \multirow{8}{*}{$\begin{array}{c}\text { Conditional } \\
\text { Mean } \\
\text { Equation }\end{array}$} & $\gamma_{0}$ & $\begin{array}{c}0.024487 \\
(0.030776) \\
\end{array}$ & $\begin{array}{c}-0.250791 \\
(0.108713)^{*}\end{array}$ & $\begin{array}{c}0.012682 \\
(0.033856) \\
\end{array}$ & $\begin{array}{c}-0.000834 \\
(0.033350) \\
\end{array}$ \\
\hline & $\mathrm{AR}(1)$ & $\begin{array}{c}0.380939 \\
(0.161538)^{*}\end{array}$ & $\begin{array}{c}0.440235 \\
(0.166589)^{* *}\end{array}$ & $\begin{array}{c}0.393779 \\
(0.161897)^{*}\end{array}$ & $\begin{array}{c}0.413803 \\
(0.157605)^{* *}\end{array}$ \\
\hline & $\operatorname{AR}(2)$ & $\begin{array}{c}-0.083106 \\
(0.153867)\end{array}$ & $\begin{array}{c}-0.115833 \\
(0.166609)\end{array}$ & $\begin{array}{c}-0.071233 \\
(0.151377)\end{array}$ & $\begin{array}{c}-0.119620 \\
(0.159645)\end{array}$ \\
\hline & $\mathrm{AR}(3)$ & $\begin{array}{c}-0.499565 \\
(0.141456)^{* *}\end{array}$ & $\begin{array}{c}-0.460687 \\
(0.145631)^{* *}\end{array}$ & $\begin{array}{c}-0.491482 \\
(0.139720)^{* *}\end{array}$ & $\begin{array}{c}-0.480865 \\
(0.134106)^{* *}\end{array}$ \\
\hline & MA(1) & $\begin{array}{c}-0.319775 \\
(0.152335)^{*}\end{array}$ & $\begin{array}{c}-0.376722 \\
(0.157301)^{*}\end{array}$ & $\begin{array}{c}-0.331317 \\
(0.152521)^{*}\end{array}$ & $\begin{array}{c}-0.351020 \\
(0.148272)^{*}\end{array}$ \\
\hline & $\operatorname{MA}(2)$ & $\begin{array}{c}0.030080 \\
(0.143105)\end{array}$ & $\begin{array}{c}0.058860 \\
(0.155319)\end{array}$ & $\begin{array}{c}0.018460 \\
(0.140159)\end{array}$ & $\begin{array}{c}0.065226 \\
(0.147854)\end{array}$ \\
\hline & MA(3) & $\begin{array}{c}0.584600 \\
(0.134643)^{* *}\end{array}$ & $\begin{array}{c}0.547871 \\
(0.138047)^{* *}\end{array}$ & $\begin{array}{c}0.577642 \\
(0.133147)^{* *}\end{array}$ & $\begin{array}{c}0.569168 \\
(0.126683)^{* *}\end{array}$ \\
\hline & $\lambda$ & & $\begin{array}{c}0.186761 \\
(0.070170)^{* *}\end{array}$ & & \\
\hline \multirow{5}{*}{$\begin{array}{c}\text { Conditional } \\
\text { Variance } \\
\text { Equation }\end{array}$} & $\alpha_{0}$ & $\begin{array}{c}0.032318 \\
(0.008400)^{* *}\end{array}$ & $\begin{array}{c}0.034899 \\
(0.008827)^{* *}\end{array}$ & $\begin{array}{c}0.035326 \\
(0.008746)^{* *}\end{array}$ & $\begin{array}{c}-0.097347 \\
(0.009735)^{* *}\end{array}$ \\
\hline & $\alpha_{1}$ & $\begin{array}{c}0.061267 \\
(0.006928)^{* *}\end{array}$ & $\begin{array}{c}0.064833 \\
(0.007419)^{* *}\end{array}$ & $\begin{array}{c}0.051252 \\
(0.008343)^{* *}\end{array}$ & $\begin{array}{c}0.145402 \\
(0.013647)^{* *}\end{array}$ \\
\hline & $\beta_{1}$ & $\begin{array}{c}0.929703 \\
(0.007415)^{* *}\end{array}$ & $\begin{array}{c}0.925498 \\
(0.007874)^{* *}\end{array}$ & $\begin{array}{c}0.927934 \\
(0.007465)^{* *}\end{array}$ & $\begin{array}{c}0.986770 \\
(0.003235)^{* *}\end{array}$ \\
\hline & $\varphi$ & & & $\begin{array}{c}0.020625 \\
(0.010476)^{*}\end{array}$ & \\
\hline & $\sigma$ & & & & $\begin{array}{c}-0.017546 \\
(0.007244)^{*} \\
\end{array}$ \\
\hline
\end{tabular}




\section{- B. Analysis of the Estimates}

1) Leptokurtosis: According to skewness values and kurtosis values, there are asymmetries and fat tail phenomenon in the two stock markets. Also, the return rates in the two stock markets are not normally distributed. It can be drawn that leptokurtosis exists in the two Chinese stock market.

2) Volatility Clustering: In both Shanghai Stock Exchange and Shenzhen Stock Exchange, $\alpha 1$ and $\beta 1$ are both smaller than 1 , but their sum is very close to 1 , indicating that the effect of a shock will continue for a long time, although its effect is decreasing during that time.Since the effect will remain for a relative long time, returns following a big one will still be relatively big and decline during a certain time, and it is the same for returns following a small one. So, volatility clustering appears in Shanghai and Shenzhen stock markets.

3) Leverage Effect:TGARCH and EGARCH models are established for both stock markets to study leverage effect. In Table III, is positive and is only significant at 5\% level, while it is not significant at $1 \%$ level. If people look at level of $1 \%$, bad news and good newshave almost same effect on return in Shanghai stock marketfromTableIII is negative, indicating that the relationship between return and volatility is negative. And this coefficient is significant at level of $1 \%$, which is strong evidence that returns under expected have more powerful effect. In Table IV, the coefficients of terms that measure asymmetry in Shenzhen market, under both TGARCH and EGARCH, are significant at level of $5 \%$, but not at level of $1 \%$. And $\sigma$ is also negative.It can be concluded that in both markets bad news does have greater impact than good news that drives return changes with same magnitude.

4)Relationship: Between Risk and Return: From Table III, $\lambda$ is significant at $10 \%$ level. But in Table IV, $\lambda$ is significant at level of $1 \%$.GARCH-M model has illustrated positive relationship between risk and return in both Shanghai and Shenzhen stock markets. And this phenomenon is more noticeable in Shenzhen market than in Shanghai market.

\section{CONCLUSION}

GARCH family has exhibited some features of Shanghai and Shenzhen stock market. There is strong evidence proving that autoregressive conditional heterosketasticitydoes exist in the two markets. The distributions of return rates in Shanghai and Shenzhen Stock Exchanges are not normal distributions, instead, leptokurtosis is presented. Also, volatility clustering usually appears. A great return fluctuation always leads to other great fluctuations following, and this shock will continue for a certain period. Because of this inevitable trend, investors are supposed to pay attention to fluctuations in stock market and take measures when big shocks happen. Stocks with high risk promise high return rates for the holders in both stock markets. Risk and return is more closely related in Shenzhen stock market than in Shanghai stock market, and from this perspective, stock market in Shenzhen may be more developed than that in Shanghai. Asymmetry can be proved to appear in Shanghai and Shenzhen stock markets .Bad news tends to have more powerful impact than good new.

\section{REFERENCES}

[1] Wang Hongtao(2010)Analysis of Return Fluctuations in Communications sector of Chinese Market Based on GARCH Family(in Chinese)

[2] Xia Tian, Hua Tianhai (2007) Trading Volume, Calendar effect and Volatility(in Chinese)

[3] Sun Zhuoyuan(2008)Research on Volatility in Chinese Market Based on GARCH Family(in Chinese)

[4] Zhu Junjun, XieShiyu (2011) Double Asymmetry of Volatility of the Chinese Stock Market and Its Explanation

[5] Fan Zhi, Zhang Shiying (2003) Multivariate GARCH modeling and its application in volatility analysis of Chinese stock markets

[6] Li Yajing, Zhu Hongquan, PengYuwei (2003) Forecasting Chinese Stock Markets Volatility Based on GARCH Models

[7] He Hongxia (2010) Research on volatility of stock price in China_GARCH class of models based on Shenzhen and Shanghai 300 index

[8] Wang Jiangfeng, Wu Qunying (2011) forecasting on the Stock Market's Volatility in Our Country Based on GARCH Models 